\title{
Influence of whole-wheat consumption on fecal microbial community structure of obese diabetic mice
}

Jose F Garcia-Mazcorro, Ivan Ivanov, David A. Mills, Giuliana Noratto

The digestive tract of mammals and other animals is colonized by trillions of metabolically active microorganisms. Changes in the gut microbiota have been associated with obesity in both humans and laboratory animals. Dietary modifications can often modulate the obese gut microbial ecosystem towards a more healthy state. This phenomenon should preferably be studied using dietary ingredients that are relevant to human nutrition. This study was designed to evaluate the influence of whole-wheat, a food ingredient with several beneficial properties, on gut microorganisms of obese diabetic mice. Diabetic $(\mathrm{db} / \mathrm{db})$ mice were fed standard (obese-control) or whole-wheat isocaloric diets (WW group) for eight weeks; non-obese mice were used as control (lean-control). Highthroughput sequencing using the MiSeq platform coupled with freely-available computational tools and quantitative real-time PCR were used to analyze fecal bacterial 16S rRNA gene sequences. Short-chain fatty acids were measured in caecal contents using quantitative high-performance liquid chromatography photo-diode array analysis. Results showed no statistical difference in final body weights between the obese-control and the WW group. The bacterial richness (number of Operational Taxonomic Units) did not differ among the treatment groups. The abundance of Ruminococcaceae, a family containing several butyrate-producing bacteria, was found to be higher in obese (median: 6.9\%) and WW-supplemented mice (5.6\%) compared to lean (2.7\%, $p=0.02$, Kruskal-Wallis test). Caecal concentrations of butyrate were higher in obese (average: $2.91 \mathrm{mmol} / \mathrm{mg}$ of feces) but especially in WW-supplemented mice $(4.27 \mathrm{mmol} / \mathrm{mg})$ compared to lean controls $(0.97$ $\mathrm{mmol} / \mathrm{mg}$ ), while caecal succinic acid was lower in the WW group compared to obese but especially to the lean group. WW consumption was associated with $\sim 3$ times higher abundances of Lactobacillus spp. compared to both obese and lean control mice. Analysis of weighted UniFrac distances revealed a distinctive clustering of lean microbial communities separately from both obese and WW-supplemented mice ( $p=0.001$, ANOSIM test). Predictive metagenome analysis revealed significant differences in several metabolic features of the microbiota among the treatment groups, including carbohydrate, amino acids and vitamin metabolism ( $p<0.01$, Kruskal-Wallis test). However, obese and WW groups tended to share more similar abundances of gene families compared to lean mice. 
Using an in vivo model of obesity and diabetes, this study suggests that daily WW supplementation for eight weeks may not be enough to influence body weight or to output a lean-like microbiome, both taxonomically and metabolically. However, WWsupplementation was associated with several statistically significant differences in the gut microbiome compared to obese controls that deserve further investigation. 
1 Influence of whole-wheat consumption on fecal microbial community structure of obese

2 diabetic mice

3

4 Jose F. Garcia-Mazcorro ${ }^{1,2}$, Ivan Ivanov ${ }^{3}$, David Mills $^{4}$ and Giuliana Noratto ${ }^{5}$

$5 \quad{ }^{1}$ Faculty of Veterinary Medicine, Universidad Autónoma de Nuevo León, General Escobedo,

$6 \quad$ Nuevo León, México

$7 \quad{ }^{2}$ Research Group Medical Eco-Biology, Faculty of Veterinary Medicine, Universidad Autónoma

8 de Nuevo León, General Escobedo, Nuevo León, México

$9 \quad{ }^{3}$ Veterinary Physiology and Pharmacology, Texas A\&M University, College Station, Texas

$10{ }^{4}$ Department of Food Science and Technology, University of California Davis, Davis, California

$11{ }^{5}$ School of Food Science, Washington State University, Pullman, Washington, United States of

12 America

\section{Corresponding author}

15 Giuliana Noratto, giuliana.noratto@tamu.edu. Current address: Department of Nutrition and

Food Science, Texas A\&M University, College Station TX USA 77845 


\section{Abstract}

The digestive tract of mammals and other animals is colonized by trillions of metabolically active microorganisms. Changes in the gut microbiota have been associated with obesity in both humans and laboratory animals. Dietary modifications can often modulate the obese gut microbial ecosystem towards a more healthy state. This phenomenon should preferably be studied using dietary ingredients that are relevant to human nutrition. This study was designed to evaluate the influence of whole-wheat, a food ingredient with several beneficial properties, on gut microorganisms of obese diabetic mice.

Diabetic $(\mathrm{db} / \mathrm{db})$ mice were fed standard (obese-control) or whole-wheat isocaloric diets (WW group) for eight weeks; non-obese mice were used as control (lean-control). High-throughput sequencing using the MiSeq platform coupled with freely-available computational tools and quantitative real-time PCR were used to analyze fecal bacterial 16S rRNA gene sequences. Short-chain fatty acids were measured in caecal contents using quantitative high-performance liquid chromatography photo-diode array analysis.

Results showed no statistical difference in final body weights between the obese-control and the WW group. The bacterial richness (number of Operational Taxonomic Units) did not differ among the treatment groups. The abundance of Ruminococcaceae, a family containing several butyrate-producing bacteria, was found to be higher in obese (median: 6.9\%) and WWsupplemented mice (5.6\%) compared to lean $(2.7 \%, p=0.02$, Kruskal-Wallis test). Caecal concentrations of butyrate were higher in obese (average: $2.91 \mathrm{mmol} / \mathrm{mg}$ of feces) but especially in WW-supplemented mice $(4.27 \mathrm{mmol} / \mathrm{mg})$ compared to lean controls $(0.97 \mathrm{mmol} / \mathrm{mg})$, while caecal succinic acid was lower in the WW group compared to obese but especially to the lean group. WW consumption was associated with $\sim 3$ times higher abundances of Lactobacillus spp. 
45 compared to both obese and lean control mice. Analysis of weighted UniFrac distances revealed

46 a distinctive clustering of lean microbial communities separately from both obese and WW-

47 supplemented mice ( $p=0.001$, ANOSIM test). Predictive metagenome analysis revealed

48 significant differences in several metabolic features of the microbiota among the treatment

49 groups, including carbohydrate, amino acids and vitamin metabolism $(p<0.01$, Kruskal-Wallis

50 test). However, obese and WW groups tended to share more similar abundances of gene families

51 compared to lean mice.

52 Using an in vivo model of obesity and diabetes, this study suggests that daily WW

53 supplementation for eight weeks may not be enough to influence body weight or to output a lean-

54 like microbiome, both taxonomically and metabolically. However, WW-supplementation was

55 associated with several statistically significant differences in the gut microbiome compared to

56 obese controls that deserve further investigation. 
68 Obesity is an epidemic with catastrophic consequences for the health of millions of people

69 around the globe. Different strategies can help reduce body weight including changes in exercise

70

71

72

73 and dietary habits, yet many patients genuinely struggle to successfully decrease their body weight due to multiple interrelated factors (Gupta, 2014).

The mammalian digestive tract is a complex organ that has been constantly co-evolving with trillions of microorganisms (the gut microbiota) to combat pathogens and maximize food digestion for at least 600 million years. Despite its general resilience, the gut microbiota is still susceptible to changes in dietary and other life habits, some of which can lead to imbalances and consequently to disease (Lozupone et al., 2012). For instance, substantial evidence has been published showing an association between obesity and changes in gut microbial populations and its metabolism of dietary and endogenous compounds (Delzenne et al., 2011). Interestingly, the changes in gut microbial communities between lean and obese individuals are not irreversible (Turnbaugh et al., 2008) with diet being the most practical alternative to reestablish microbial equilibrium within the gut. Understanding changes in gut microorganisms in response to dietary modifications is essential to develop effective dietary strategies to help obese patients.

Growing evidence shows that the consumption of specific dietary ingredients or supplements such as probiotics, prebiotics, polyphenols, as well as whole-grains has the potential of modifying gut health parameters in obese individuals, both in humans and animal models (Katcher et al., 2008; Noratto et al., 2014; Petschow et al., 2013; Vitaglione et al., 2015). Whole-wheat (WW) is often recommended by medical nutritionists as part of a healthy diet for both overweighed and lean individuals. While several investigations have previously addressed 
91 the nutritional benefits of consuming WW (Stevenson et al., 2012), very few studies have

92 researched the potential of either WW or its individual nutrients to alter the gut microbiota of

93 lean or obese individuals (Neyrinck et al., 2011) or as part of dietary management to treat

94 obesity. One study investigated the effect of replacing refined wheat with whole-grain wheat for

9512 weeks on body weight and fat mass in overweighed women (Kristensen et al., 2011). This

96 short-period of 12 weeks was enough to significantly reduce percentage fat mass but no body

97 weights. Here we show that an 8-week consumption period of an isocaloric WW diet did not

98 significantly change body weights in obese-diabetic mice. Overall, obese mice under WW-

99 supplemented diet showed similarities to obese controls with regards to gut microbial

100 composition and predicted metabolic profile. The effect of WW was mostly observed on caecal

101 concentrations of butyrate and succinate and a few bacterial groups such as Lactobacillus. The

102 results may have implications in clinical dietary management of obesity using WW.

103

104 METHODS

105 Study design

106 The Institutional Animal Care Use Committee from Washington State University approved all 107 experimental procedures (animal protocol approval number: 04436-001). Two strains of male 108 mice were used in this study, BKS.Cg- + Lepr $^{d b} /+$ Lepr $^{d b} / O l a H s d$ obese diabetic $(\mathrm{db} / \mathrm{db})$, and 109 lean BKS.Cg-Dock7m +/+ Lepr ${ }^{d b} /$ OlaHsd (Harlan Laboratories, Kent, WA). Animals were 110 purchased at 5-6 weeks of age and maintained in ventilated rack system with food and water

111 provided ad libitum throughout the study. We received 11 mice for the lean group and 10 mice

112 from all other groups. After 7 days of acclimatization, obese mice were randomly divided into

113 two groups ( $\mathrm{n}=10$ each) namely obese (AIN-93 G Purified Rodent Diet) and WW (whole-wheat 
114 supplemented diet). The wild type mice group $(\mathrm{n}=11)$ was named lean (AIN-93 Diet). Diets were

115 made by Dyets Inc. (Bethlehem, PA) (Table 1). Four or five mice per cage were housed in an

116 environment-controlled room $\left(23^{\circ} \mathrm{C}, 12\right.$ hours dark-light cycle). All mice were visually

117 inspected every day and body weight was recorded from all animals once a week.

119 Fecal collection and DNA extraction

120 Fresh distal colon contents (see qPCR analysis below) and fecal samples were obtained from all

121 mice at the end of the study ( 8 weeks) and stored at $-80^{\circ} \mathrm{C}$ prior to DNA and $16 \mathrm{~S}$ rRNA gene

122 profiling analysis. Total DNA was extracted from at least two different fecal pellets weighting

123 approximately $200 \mathrm{mg}$. Following bead-beating, the QIAamp DNA Stool Mini Kit (Qiagen Inc.,

124 Valencia, CA) was used for DNA extraction following the manufacturer's instructions. DNA

125 concentration and purity was determined using a NanoDrop Spectrophotometer (Thermo

126 Scientific, Wilmington, DE) and diluted to a working concentration of $5 \mathrm{ng} / \mu \mathrm{L}$.

127

High-throughput sequencing of 16S rRNA genes

129 Amplification and sequencing were performed as described elsewhere (Bokulich et al., 2014).

130 Briefly, the V4 semi-conserved region of bacterial 16S rRNA genes was amplified using primers

131 F515 (5'-GTGCCAGCMGCCGCGGTAA-3') and R806 (5'-

132 GGACTACHVGGGTWTCTAAT-3'), with the forward primer modified to contain a unique 8-

133 nt barcode and a 2-nt linker sequence at the 5' terminus. Amplicons were combined into two

134 separated pooled samples and submitted to the University of California Davis Genome Center

135 DNA Technologies Core for Illumina paired-end library preparation, cluster generation, and 250-

136 bp paired-end sequencing on an Illumina MiSeq instrument in two separate runs. For data 
137 analysis, raw Illumina fastq files were demultiplexed, quality filtered, and analyzed using the

138 freely available Quantitative Insights into Microbial Ecology (QIIME) Virtual Box v.1.8.0

139 (Caporaso et al., 2010). Operational taxonomic units (OTUs) were assigned using two different

140 approaches: first, using UCLUST v.1.2.22 (Edgar, 2010) as implemented in QIIME using the

141 open-reference clustering algorithm described in (Rideout et al., 2014) for alpha and beta

142 diversity analyses; and second, using the pick_closed_reference_otus.py QIIME script for further

143 analysis using PICRUSt (see Predicted metabolic profiles below). The Greengenes 13_5 97\%

144 OTU representative 16S rRNA gene sequences was used as the reference sequence collection

145 (DeSantis et al., 2006). Alfa and beta diversity analyses were performed using 3000 random

146 sequences per sample (lowest number of sequences in a sample after demultiplexing, filtering

147 and OTU picking). Raw sequences were uploaded into the Sequence Read Archive at NCBI

148 (accession number: PRJNA281761). The trim.seqs command in MOTHUR (Schloss et al., 2009)

149 was used for splitting original fastq files per sample for uploading to SRA.

150

151 Predicted metabolic profiles

152 OTUs from the closed_reference script were normalized and used to predict metagenome

153 functional content using the online Galaxy version of PICRUSt (Phylogenetic Investigation of

154 Communities by Reconstruction of Unobserved States) (Langille et al., 2013). PICRUSt uses

155 existing annotations of gene content as well as 16S copy numbers from reference microbial

156 genomes in the IMG database (Markowitz et al., 2012) and a functional classification scheme to

157 catalogue the predicted metagenome content. The current galaxy version supports three types of

158 functional predictions; this current study used the popular KEGG Orthologs (Kanehisa et al.,

159 2012). 


\section{Quantitative real-time PCR (qPCR) analysis}

162

163

164

165

166

167

168

169

170

171

172

173

174

DNA was extracted from distal colon content using the ZR Fecal DNA MiniPrep ${ }^{\mathrm{TM}}$ kit following the manufacturer's protocol (Zymo Research, Irvin, CA). qPCR was used to detect specific bacterial groups as described elsewhere (Noratto et al., 2014). Table 2 shows the primers sequences used for all qPCR analyses.

\section{Measurement of short chain fatty acids (SCFAs) in caecal contents}

SCFAs were quantified as reported elsewhere (Campos et al., 2012). Briefly, samples were analyzed by an HPLC-PDA system using an Aminex HPX-87H strong cation-exchange resin column (300 x $7.8 \mathrm{~mm})$ and fitted with an ion exchange microguard refill cartridge (Bio-Rad, Hercules, CA). The HPLC-PDA system consisted of a Water 2695 Separation Module (Waters, Milford, MA), which was equipped with a Water 2996 photodiode array detector (PDA). Samples $(20 \mu \mathrm{L})$ were eluted isocratically with $5 \mathrm{mM}$ sulfuric acid at $0.6 \mathrm{~mL} / \mathrm{min}$, and the column temperature was held at $50{ }^{\circ} \mathrm{C}$. Sodium butyrate, acetic acid, oxalic acid, and succinic acid were identified and quantified by comparing retention time and UV-Visible spectral data to standards.

\section{Statistical analysis}

ANOVA and the non-parametric alternative Kruskal-Wallis test were used to analyze final body weights and SCFAs concentrations, respectively. Multiple-comparisons were performed using Tukey and Mann-Whitney tests. The Bonferroni (for Mann-Whitney tests) and False Discovery Rate (for Tukey's tests) corrections were used to adjust for multiple comparisons. Analysis of 
183 Similarities (ANOSIM) was used to test for clustering of microbial communities using weighted

184 and unweighted UniFrac distance matrices. QIIME v.1.8.0, R v.3.0.3 ( $R$ core team), PAST

185 (Hammer et al., 2001) and Excel were used for statistics and graphics. The linear discriminant

186 analysis (LDA) effect size (LEfSe) method was used to assess differences in microbial

187 communities using a LDA score threshold of 3 (Segata et al., 2011). STAMP (Parks et al., 2010)

188 was used to visualize and analyze the PICRUSt data with ANOVA and False Discovery Rate.

189 Unless otherwise noted, an alpha of 0.05 was considered to reject null hypotheses.

190

191

\section{RESULTS}

One mouse in the obese group died for reasons unrelated to this study. At the end of the study, there was a significant $(p<0.01$, ANOVA) difference in body weight between the lean (average: $30.6 \pm 2.2 \mathrm{~g})$ and both the obese $(46.1 \pm 2.8 \mathrm{~g})$ and WW groups $(45.3 \pm 5.8 \mathrm{~g}) . \mathrm{WW}$ consumption was not associated with a lower body weight compared to obese control group ( $p=0.96$, Tukey's test).

Fecal microbiota composition

A total of 8686 different OTUs were detected using the open reference algorithm described by

Rideout et al. (2014). On the other hand, the closed_reference method used to generate data for PICRUSt (see PICRUSt below) only yielded 1302 OTUs. Fecal microbial composition of all mice was mostly comprised by Firmicutes (average: 58.7\% across all samples) and Bacteroidetes (average: 32.8\%) (Fig. 1). Other less abundant Phyla were Actinobacteria ( 4\%), Proteobacteria $(\sim 3 \%)$,Verrucomicrobia $(\sim 0.8 \%)$ and others (Fig. 1). There was no statistical difference in relative abundance of the two most abundant phyla (Firmicutes and Bacteroidetes), partly 
206 because of the high variability among individual mice. The ratio Bacteroidetes/Firmicutes was

207 lower in the lean (median: 38.7\%) compared to the obese group (median: $85.3 \%$ ) and the WW

208 group (median: 75.4\%) but this difference did not reach significance $(p=0.12$, Kruskal-Wallis).

209 Several statistical differences were found in low abundant phyla. Actinobacteria and

210 Verrucomicrobia were higher in lean, Cyanobacteria, TM7 and Tenericutes were higher in the

211 WW group, and Deferribacteres was higher in obese-control ( $p<0.01$, Kruskal Wallis, Fig. 1).

212

213 LEfSe showed statistical significant differences for several microbial groups at lower taxonomic

214 levels (Fig. 2). Among the bacterial groups that showed differences indicating an effect of WW-

215 supplementation include the genus Lactobacillus, the class Gammaproteobacteria and the

216 controversial S24-7 family (see Thread in QIIME google group in references) (Fig. 2). Other

217 differences in bacterial abundances suggested that WW-supplementation did not generate a lean-

218 like microbiome. For example, the genera Bifidobacterium, Allobaculum and Akkermansia were

219 higher in lean compared to both obese and WW group (Fig. 2). Also, the family Ruminococcacea

220 was more similar between obese (median: 6.9\%) and WW-supplemented mice (5.6\%) compared

221 to lean (2.7\%). Despite these differences, overall the fecal microbial composition of obese-

222 control and WW mice was more similar to each other compared to lean although WW-

223 supplementation yielded a unique pattern of bacterial abundances that did not necessarily cluster 224 together with all obese samples (Fig. 3).

226 Alpha diversity

227 There was no significant difference in number of OTUs and Chaol diversity index. Interestingly, 228 samples from the obese group showed a more disperse distribution of OTUs (Fig. 4). Rarefied 
229 plots of number of OTUs showed that more than the 3000 sequences per sample used in this

230 study are needed to fully describe the fecal microbiota of all mice.

231

232 Beta-diversity

233 Principal Coordinate Analysis (PCoA) of weighted and unweighted UniFrac metrics showed

234 different clustering of microbial communities. Weighted (which takes phylogenetic information

235 as well as sequence abundance into account) metrics clearly showed a different microbial

236 structure in lean individuals compared to obese and WW groups (ANOSIM $p=0.001$ ) (Fig. 5).

237 This was expected based on the clustering of lean subjects using relative abundance of sequence

238 reads (Fig. 3). On the other hand, the qualitative (does not take sequence abundance into

239 account) unweighted UniFrac analysis shows that the microbiota of the WW group clustered

240 separately from the lean and obese groups (ANOSIM $p=0.001$ ) (Fig. 5).

\section{Predicted metabolic profile}

243 The taxa predicted by 16S RNA marker gene sequencing was used to predict the functional

244 profile of the fecal microbiome in all three experimental groups. Using a $p<0.01$ for ANOVA

245 tests in STAMP, several statistical differences were found (Table 3). Overall, obese and WW

246 groups tended to share more similar abundances of gene families compared to lean mice, an

247 observation that supports the differences in bacterial abundances.

qPCR assessment of microbiota in distal colon contents

250 We performed qPCR analysis for bacterial groups of interest to health in distal colon contents.

251 Similarly to the sequencing results from fecal samples, qPCR results revealed several differences 
252 in relative abundance for different bacterial groups (Fig. 6).

253

\section{SCFAs caecal concentrations}

255 There was a statistically significant difference among the treatment groups for several SCFAs in 256 caecal contents (Table 4). Butyrate concentrations were higher in the WW group compared to 257 both the lean and the obese group ( $p<0.001$, Kruskal-Wallis). Also, WW consumption was 258 associated with lower succinic acid concentrations ( $p=0.009$, Kruskal-Wallis).

\section{DISCUSSION}

261 Obesity is a worldwide epidemic disease that has been associated with changes in the gut microbiome in many different studies. Consumption of whole grains is often recommended by medical nutritionists as part of a healthy diet. To our knowledge, this is the first study evaluating the in vivo effect of WW consumption on fecal bacterial community structure of obese diabetic mice, adding valuable information to the literature with regard to the use and development of dietary strategies to help obese patients.

Ley et al. (2005) showed that lean mice have more Bacteroidetes and less Firmicutes compared to obese mice, a finding that has been reported by several other research groups. However, it is important to note that these observations were division-wide (in other words, there was no specific subgroup such as families or genera that were present high or low in abundance) and, more importantly, that other researchers have found either no difference in Firmicutes and Bacteroidetes between obese and lean (Duncan et al., 2008) or more Bacteroidetes in obese 274 compared to normal-weight individuals (Zhang et al., 2009). Interestingly, in this study 
275 sequencing showed no statistical difference in the abundance of both phyla Firmicutes and

276 Bacteroidetes between lean and obese control; nonetheless, two important aspects must be taken

277 into account. First, obese and WW mice were consistently more like each other compared to lean

278 mice with regard to the abundance of both phyla. Also, contrary to the observations by Ley et al.

279 (2005), lean mice had more Firmicutes and less Bacteroidetes compared to both obese and WW

280 mice, a difference that did not reach statistical significance. qPCR confirmed the sequencing

281 results about the abundance of Firmicutes but not Bacteroidetes, maybe due to the use of fecal

282 (sequencing) or colon (qPCR) contents for bacterial analysis. Regardless, differences in taxa

283 abundance at the phylum level have little relevance when considering all their individual groups

284 within. For instance, many bacterial groups at lower taxonomic levels deserve attention, like the

285 mucin-degrader Akkermansia which has been shown to be inversely correlated with body weight

286 in rodents and humans (Everard et al., 2013). Accordingly, both sequencing and qPCR in this

287 current study showed that obese mice had fewer Akkermansia and WW consumption surprisingly

288 helped to decrease its abundance even further. Here it is important to note that a higher

289 abundance in feces does not necessarily imply a higher abundance in the mucus. WW

290 consumption was also associated with much more Lactobacillus spp., a bacterial genus

291 frequently used in probiotic formulations, and the genus Allobaculum was practically absent in

292 both obese and WW groups while lean individuals were heavily colonized by this group. These

293 changes in bacterial abundances deserve more investigation.

Beta diversity metrics are useful to study similarities of microbiomes, which in turn have critical consequences for understanding health and disease processes. Lozupone et al. (2007) explains

297 that quantitative beta-diversity measures (weighted UniFrac distances) are better for revealing 
298 community differences that are due to changes in relative taxon (OTUs) abundance, while

299 qualitative (unweighted) are most informative when communities differ by what can live in

300 them. Most studies report either weighted or unweighted but few report both. In this study,

301 weighted analysis showed a clear separation of lean samples from all samples from the obese and

302 WW groups, suggesting that the numbers of OTUs are an important determinant to separate lean

303 microbiomes from obese individuals with and without WW. In this study, the results of weighted

304 analysis also show that animal genetics was the predominant factor to separate microbial

305 communities. On the other hand, unweighted analysis showed opposite results: lean and obese

306 samples clustered separately from all samples of the WW group, suggesting that WW helped

307 create an environment that favored a phylogenetically different ecosystem. Importantly, the

308 variation explained by the axes is much lower when using unweighted UniFrac. At this point,

309 both methods should be considered for explaining the changes in gut microbiomes in

310 investigations like this study (Lozupone et al. 2007). The discrepancy between the results of

311 weighted and unweighted results suggests that an 8-week period of WW consumption helped

312 change the overall environment in the intestinal lumen, thus modulating what can live and

313 proliferate in it (unweighted results). Thus, the different environment could promote changes in

314 the abundance of specific taxa (weighted results), as shown in this study for several bacterial

315 groups. Given that the assessment of microbial diversity is a major component in microbial

316 ecological studies and closely relates to our understanding of health and health deviations, we

317 expect others to start inspecting and reporting both weighted and unweighted UniFrac distance

318 metrics. The use of both metrics has been shown to be useful in various investigations (Campbell

319 et al., 2015; Igarashi et al., 2014; Wu et al., 2010). 
321 Microbial butyrate is essential for colon health and lower concentrations of this fatty acid are

322 usually considered non-optimal for gut health (Donohoe et al., 2011). Nonetheless, studies have

323 shown that obese individuals actually have higher fecal butyrate and other SCFAs compared to

324 lean individuals (Fernandes et al., 2014), an observation that suggests that both lower and higher

325 butyrate concentrations than normal may be associated with and perhaps aggravate disease.

326 Similarly, obese mice in this current study (with and without WW supplementation) had higher

327 butyrate concentrations in caecal contents compared to lean mice. Butyrate-producers are

328 abundant in the mammalian gut and mainly belong to the family Ruminococcaceae within the

329 Firmicutes (Louis et al., 2009). In this study both sequencing and qPCR revealed higher fecal

330 Ruminococcaceae in obese and WW groups compared to lean individuals, thus potentially

331 explaining the higher caecal butyrate concentrations. Another SCFA that deserves attention is

332 succinic acid, which has been shown to increase in rats fed a high-fat diet (Jakobsdottir et al.,

333 2013). In this current study, obese mice had lower concentrations of succinic acid and WW-

334 supplementation seemingly helped to drastically decrease it. Unfortunately, far more attention

335 has been paid to butyrate compared to succinate, propionate and other SCFA (Cheng et al., 2013;

336 Reichardt et al., 2014).

338 The assessment of microbial metabolic activity in complex ecosystems is hampered in part by

339 the huge number of microorganisms and the cost of sequencing either whole genomes or

340 transcriptomes. PICRUSt allows a prediction of the metabolic profile using taxa predicted by

341 16S rRNA gene sequencing. PICRUSt is, however, not exempt of pitfalls: it only uses

342 information for well-defined 16S sequences and the presence of a given set of genes does not tell

343 anything about their functional activity depending on the specific environmental conditions. 
344 Supported by the similarities in abundance of most bacterial groups between obese-control and

345 WW groups, this study showed that 8-week WW consumption was not enough to make a

346 significant difference in the abundance of bacterial gene families.

347

348

349

350

351

352

353

354

355

356

357

358

359

360

361

362

363

364

365

366

\section{Caveats}

This study was designed to obtain preliminary information about the influence of WW consumption on gut microbial ecology of obese diabetic mice; therefore, we did not aim to determine the exact compound(s) behind the observed effects. Wheat is a fiber-rich grain and consumption of fiber alone is associated with changes in the gut microbiome and the immune system of the host (Bermudez-Brito et al., 2015). Aside fiber, WW also contains other bioactive compounds (e.g. polyphenols) that may be responsible for specific effects on host metabolism, physiology and immune system. For instance, it has been recently shown that wheat-derived alkylresorcinols were capable of showing beneficial effects on diet-induced obese mice (Oishi et al., 2015). Interestingly, our group showed that carbohydrate-free polyphenol-rich juice from plum is capable of impeding body weight gain in obese Zucker rats (Noratto et al., 2014), a finding that was not observed with WW consumption in mice in this current study. More research is necessary to investigate the separate effect of the different nutrients in WW.

\section{SUMMARY}

In summary, this study suggests that an 8-week consumption of whole-wheat may not be enough to exert an effect on body weight and to output a lean-like microbiome using an in vivo model of obesity and diabetes. However, WW-supplementation was associated with several statistically significant changes compared to obese controls that deserve further investigations. These results 
367 may or may not apply to obesity in human patients. Also, our experimental scheme was not

368 designed to address the effect of WW supplementation on lean mice; whether the observed

369 changes in the gut microbiome and metabolite concentrations are irrespective of mice phenotype

370 may warrant further research. The clinical relevance of this present work remains to be

371 determined.

372

373

\section{Future directions}

In humans, obesity is a multifactorial disease that can be partly controlled with dietary

375

376

377

378

379

380

381

382

383

384

385

386

387

388

389

modifications. This paper adds valuable information to the current literature with regard to the potential influence of WW consumption on the gut microbiota of obese diabetic mice. However, research is needed to investigate the effect of WW on obese human individuals.

\section{REFERENCES}

Bacchetti DG, Aldred N, Clare AS, Burgess JG. 2011. Improvement of phylum- and classspecific primers for real-time PCR quantification of bacterial taxa. Journal of Microbiological Methods 86:351-356 DOI 10.1016/j.mimet.2011.06.010.

Bartosch S, Fite A, Macfarlane GT, McMurdo ME. 2004. Characterization of bacterial communities in feces from healthy elderly volunteers and hospitalized elderly patients by using real-time PCR and effects of antibiotic treatment on the fecal microbiota. Applied Environmental Microbiology 70:3575-81 DOI 10.1128/AEM.70.6.3575-3581.2004.

Bermudez-Brito M, Sahasrabudhe NM, Rösch C, Schols, HA, Faas MM, de Vos P. 2015. The impact of dietary fibers on dendritic cell responses in vitro is dependent on the differential effects of the fibers on intestinal epithelial cells. Molecular Nutrition and Food Research 
390

391

392

393

394

395

396

397

398

399

400

401

402

403

404

405

406

407

408

409

410

411

412

30:698-710 DOI 10.1002/mnfr.201400811.

Bokulich NA, Thorngate JH, Richardson PM, Mills DA. 2014. Microbial biogeography of wine grapes is conditioned by cultivar, vintage, and climate. Proceedings of the National Academy of Sciences of the United States of America 111:E139-E148 DOI 10.1073/pnas.1317377110.

Campbell AM, Fleisher J, Sinigalliano C, White JR, Lopez JV. 2015. Dynamics of marine bacterial community diversity of the coastal waters of the reefs, inlets, and wastewater outfalls of southeast Florida. MicrobiologyOpen 4:390-408 DOI 10.1002/mbo3.245.

Campos D, Betalleluz-Pallardel I, Chirinos R, Aguilar-Galvez A, Noratto G, Pedreschi R. 2012. Prebiotic effects of yacon (Smallanthus sonchifolius Poepp. \& Endl), a source of fructooligosaccharides and phenolic compounds with antioxidant activity. Food Chemistry 135:1592-1599 DOI 10.1016/j.foodchem.2012.05.088.

Caporaso JG, Kuczynski J, Stombaugh J, Bittinger K, Bushman FD, Costello EK, Fierer N, Peña AG, Goodrich JK, Gordon JI, Huttley GA, Kelley ST, Knights D, Koening JE, Ley RE, Lozupone CA, McDonald D, Muegge BD, Pirrung M, Reeder J, Sevinsky JR, Turbnbaugh PJ, Walters WA, Widmann J, Yatsunenko T, Zaneveld J, Knight R. 2010. QIIME allows analysis of high-throughput community sequencing data. Nature Methods 7:335-336 DOI 10.1038/nmeth.f.303.

Cheng KK, Wang GY, Zeng J, Zhang JA. 2013. Improved succinate production by metabolic engineering. BioMed Research International 538790 DOI 10.1155/2013/538790.

Collado MC, Derrien M, Isolauri E, de Vos WM, Saliminen S. 2007. Intestinal integrity and Akkermansia muciniphila, a mucin-degrading member of the intestinal microbiota present in infants, adults, and the elderly. Applied Environmental Microbiology 73:7767-7770 DOI 10.1128/AEM.01477-07. 
413 Delzenne NM, Cani PD. 2011. Interaction between obesity and the gut microbiota: Relevance in

414 nutrition. Annual Review of Nutrition 31:15-31 DOI 10.1146/annurev-nutr-072610-145146.

415 DeSantis TZ, Hugenholtz P, Larsen N, Rojas M, Brodie EL, Keller K, Huber T, Dalevi D, Hu P, 416 Andersen GL. 2006. Greengenes, a chimera-checked 16S rRNA gene database and workbench 417 compatible with ARB. Applied Environmental Microbiology 72:5069-5072 DOI

418 10.1128/AEM.03006-05.

419 Donohoe DR, Garge N, Zhang X, Sun W,O’Connell TM, Bunger MK, Bultman SJ. 2013. The 420 microbiome and butyrate regulate energy metabolism and autophagy in the mammalian colon. 421 Cell Metabolism 13:517-526 DOI 10.1016/j.cmet.2011.02.018.

422 Duncan SH, Lobley GE, Holtrop G, Ince J, Johnstone AM, Louis P, Flint HJ. 2008. Human 423 colonic microbiota associated with diet, obesity and weight loss. International Journal of Obesity 424 (London) 32:1720-1724 DOI 10.1038/ijo.2008.155.

425 Edgar RC. 2010. Search and clustering orders of magnitude faster than BLAST. Bioinformatics 426 26:2460-2461 DOI 10.1093/bioinformatics/btq461.

427 Everard A, Belzer C, Geurts L, Ouwerkerk JP, Druart C, Bindels LB, Guiot Y, Derrien M, 428 Muccioli GG, Delzenne NM. 2013. Cross-talk between Akkermansia muciniphila and intestinal 429 epithelium controls diet-induced obesity. Proceedings of the National Academy of Sciences of 430 the United States of America 110:9066-9071 DOI 10.1073/pnas.1219451110.

431 Fernandes J, Su W, Rahat-Rozenbloom S, Wolever TM, Comelli EM. 2014. Adiposity, gut 432 microbiota and faecal short chain fatty acids are linked in adult humans. Nutrition \&. Diabetes 433 4:e121 DOI 10.1038/nutd.2014.23.

434 Garcia-Mazcorro JF, Suchodolski JS, Jones KR, Clark-Price SC, Dowd SE, Minamoto Y, 435 Markel M, Steiner JM, Dossin O. 2012. Effect of the proton pump inhibitor omeprazole on the 
436

437

438

439

440

441

442

443

444

445

446

447

448

449

450

451

452

453

454

455

456

457

458

gastrointestinal bacterial microbiota of healthy dogs. FEMS Microbiology Ecology 80:624-636

DOI 10.1111/j.1574-6941.2012.01331.x.

Guo X, Xia X, Tang R, Zhou J, Zhao H, Wang K. 2008. Development of a real-time PCR

method for Firmicutes and Bacteroidetes in faeces and its application to quantify intestinal population of obese and lean pigs. Letters in Applied Microbiology 47:367-373 DOI 10.1111/j.1472-765X.2008.02408.x.

Gupta H. 2014. Barriers to and facilitators of long term weight loss maintenance in adult UK people: a thematic analysis. International Journal of Preventive Medicine 5:1512-1520.

Hammer $\varnothing$, Harper DAT, Ryan PD. 2001. PAST: Paleontological Statistics Software Package for Education and Data Analysis. Paleontologia Electronica 4: 1-9.

Huijsdens XW, Linskens RK, Mak M, Meuwissen SGM., Vandenbroucke-Grauls CMJE, Savelkoul PHM. 2002. Quantification of bacteria adherent to gastrointestinal mucosa by realtime PCR. Journal of Clinical Microbiology 40:4423-4427 DOI 10.1128/JCM.40.12.44234427.2002.

Igarashi H, Maeda S, Ohno K, Horigome A, Odamaki T, Tsujimoto H. 2014. Effect of oral administration of metronidazole or prednisolone on fecal microbiota in dogs. PLOS ONE 9:e107909 DOI 10.1371/journal.pone.0107909.

Jakobsdottir G, Xu J, Molin G, Ahrné S, Nyman M. 2013. High-fat diet reduces the formation of butyrate, but increases succinate, inflammation, live fat and cholesterol in rats, while dietary fibre counteracts these effects. PLoS ONE 8:e80476 DOI 10.1371/journal.pone.0080476.

Kanehisa M, Goto S, Sato Y, Furumichi M, Tanabe M. 2012. KEGG for integration and interpretation of large-scale molecular data sets. Nucleic Acids Research 40:D109-D114 DOI 10.1093/nar/gkr988. 
459 Katcher HI, Legro RS, Kunselman AR, Gillies, PJ, Demers LM, Bagshaw DM, Kris-Etherton

460 PM. 2008. The effects of a whole grain-enriched hypocaloric diet on cardiovascular disease risk

461 factors in men and women with metabolic syndrome. The American Journal of Clinical

462 Nutrition. 87:79-90.

463 Kristensen M, Toubro S, Jensen MG, Ross AB, Riboldi G, Petronio M, Bügel S, Tetens I, Astrup

464 A. 2011. Whole grain compared with refined wheat decreases the percentage of body fat

465 following a 12-week, energy-restricted dietary intervention in postmenopausal women. The

466 Journal of Nutrition 142:710-716 DOI: 10.3945/jn.111.142315.

467 Langille MGI, Zaneveld J, Caporaso JG, McDonald D, Knights D, Reyes JA, Clemente JC,

468 Burkepile DE, Vega Thurber RL, Knight R, Beiko RG, Huttenhower C. 2013. Predictive

469 functional profiling of microbial communities using 16S rRNA marker gene sequences. Nature

470 Biotechnology 31:814-823 DOI: 10.1038/nbt.2676.

471 Larsen N, Vogensen FK, van den Berg FW, Nielsen DS, Andreasen AS, Pedersen BK, Al-Soud 472 WA, Sørensen SJ, Hansen LH, Jakobsen M. 2010. Gut microbiota in human adults with type 2 473 diabetes differs from non-diabetic adults. PLoS ONE 5:e9085 DOI 474 10.1371/journal.pone.0009085.

475 Ley RE, Bäckhed F, Turnbaugh P, Lozupone CA, Knight RD, Gordon JI. 2005. Obesity alters 476 gut microbial ecology. Proceedings of the National Academy of Sciences of the United States of 477 America 102:11070-11075 DOI 10.1073/pnas.0504978102.

478 Liu C, Song Y, McTeague M, Vu AW, Wexler H, Finegold SM. 2003. Rapid identification of 479 the species of the Bacteroides fragilis group by multiplex PCR assays using group- and species480 specific primers. FEMS Microbiology Letters 222:9-16 DOI 10.1016/S0378-1097(03)00296-9.

481 Louis P, Flint HJ. 2009. Diversity, metabolism and microbial ecology of butyrate-producing 
482 bacteria from the human large intestine. FEMS Microbiology Letters 294:1-8 DOI

483 10.1111/j.1574-6968.2009.01514.x.

484 Lozupone CA, Stombaugh JI, Gordon JI, Jansson JK, Knight R. 2012. Diversity, stability and 485 resilience of the human gut microbiota. Nature 489:220-230 DOI 10.1038/nature11550.

486 Lozupone CA, Hamady M, Kelley ST, Knight R. 2007. Quantitative and qualitative beta

487 diversity measures lead to different insights into factors that structure microbial communities. 488 Applied Environmental Microbiology 73:1576-1585 DOI 10.1128/AEM.01996-06.

489 Markowitz VM, Chen IM, Palaniappan K, Chu K, Szeto E, Grechkin Y, Ratner A, Jacob B, 490 Huang J, Williams P, Huntemann M, Anderson I, Mavromatis K, Ivanova NN, Kyrpides NC. 491 IMG: the Integrated Microbial Genomes database and comparative analysis system. Nucleic 492 Acids Research. 40:D115-D122 DOI 10.1093/nar/gkr1044.

493 Neyrinck AM, Possemiers S, Druart C, van de Wiele T, De Backer F, Cani PD, Larondelle Y, 494 Delzenne NM. 2011. Prebiotic effects of wheat arabinoxylan related to the increase in 495 bifidobacteria, Roseburia and Bacteroides/Prevotella in diet-induced obese mice. PLoS ONE 6:e20944 DOI 10.1371/journal.pone.0020944.

497 Noratto G, Garcia-Mazcorro JF, Markel M, Martino HS, Minamoto Y, Steiner JM, Byrne D, 498 Suchodolski JS, Mertens-Talcott SU. 2014. Carbohydrate-free peach and plum juice affects fecal 499 microbial ecology in an obese animal model. PLoS ONE 2014, 9:e101723 DOI $500 \quad 10.1371 /$ journal.pone.0101723.

501 Oishi K, Yamamoto S, Itoh N, Nakao R, Yasumoto Y, Tanaka K, Kikuchi Y, Fukudome S, Okita 502 K, Takano-Ishikawa Y. 2015. Wheat alkylresorcinols suppress high-fat, high-sucrose diet503 induced obesity and glucose intolerance by increasing insulin sensitivity and cholesterol 504 excretion in male mice. Journal of Nutrition 145:199-206 DOI 10.3945/jn.114.202754. 
505 Parks DH, Beiko RG. 2010. Identifying biologically relevant differences between metagenomic

506 communities. Bioinformatics 26:715-721 DOI 10.1093/bioinformatics/btq041.

507 Penders J, Vink C, Driessen C, London N, Thijs C, Stobberingh EE. 2005. Quantificacion of

508 Bifidobacterium spp., Escherichia coli and Clostridium difficile in faecal samples of breast-fed

509 and formula-fed infants by real-time PCR. FEMS Microbiology Letters 243:141-147.

510 Petschow B, Doré J, Hibberd P, Dinan T, Reid G, Blaser M, Cani PD, Degnan FH, Foster J,

511 Gibson G, Hutton J, Klaenhammer TR, Ley R, Nieuwdorp M, Pot B, Relman D, Serazin A,

512 Sanders ME. 2013. Probiotics, prebiotics, and the host microbiome: the science of translation.

513 Annals of the New York Academy of Sciences 1306:1-17 DOI 10.1111/nyas.12303.

514 R Core Team, R: A language and environment for statistical computing. R Foundation for

515 Statistical Computing, Vienna, Austria. 2014, URL http://www.R-project.org/.

516 Reichardt N, Duncan SH, Young P, Belenguer A, Leitch CM, Scott KP, Flint HJ, Louis P. 2014.

517 Phylogenetic distribution of three pathways for propionate production within the human gut

518 microbiota. ISME Journal 8:1323-1335 DOI 10.1038/ismej.2014.14.

519 Rideout JR, He Y, Navas-Molina JA, Walters WA, Ursell LK, Gibbons SM, Chase J, McDonald

520 D, Gonzalez A, Robbins-Pianka A, Clemente JC, Gilbert JA, huse SM, Zhou HW, Knight R,

521 Caporaso JG. 2014. Subsampled open-reference clustering creates consistent, comprehensive

522 OTU definitions and scales to billions of sequences. PeerJ 2:e545 DOI 10.7717/peerj.545.

523 Scholss PD, Westcott SL, Ryabin T, Hall JR, Hartmann M, Hollister EB, Lesniewski RA,

524 Oakley BB, Parks DH, Robinson CJ, Sahl JW, Stres B, Thallinger GG, Van Horn DJ, Weber CF.

525 2009. Introducing mothur: open source, platform-independent, community-supported software

526 for describing and comparing microbial communities. Applied Environmental Microbiology

527 75:7537-7541 DOI 10.1128/AEM.01541-09. 
528 Segata N, Izard J, Waldron L, Gevers D, Miropolsky L, Garrett WS, Huttenhower C. 2011.

529 Metagenomic biomarker discovery and explanation. Genome Biology 12:R60 DOI 10.1186/gb-

$530 \quad 2011-12-6-r 60$.

531 Stevenson L, Phillips F, O’Sullivan K, Walton J. 2012. Wheat bran: its composition and benefits

532 to health, a European perspective. International Journal of Food Sciences and Nutrition

533 63:1001-1013 DOI 10.3109/09637486.2012.687366.

534 Suchodolski JS, Markel ME, Garcia-Mazcorro JF, Unterer S, Heilmann RM, Dowd SE, Kachroo

535 P, Ivanov I, Minamoto Y, Dillman EM, Steiner JM, Cook AK, Toresson L. 2012. The fecal

536 microbiome in dogs with acute diarrhea and idiopathic inflammatory bowel disease. PLoS ONE

537 7:e51907 DOI 10.1371/journal.pone.0051907.

538 Thread in QIIME google group, URL https:/groups.google.com/forum/\#!topic/qiime539 forum/Ds75aZoVrFY.

540 Turnbaugh PJ, Bäckhed F, Fulton L, Gordon JI. 2008. Diet-induced obesity is linked to marked 541 but reversible alterations in the mouse distal gut microbiome. Cell Host \& Microbe 17:213-223

542 DOI 10.1016/j.chom.2008.02.015.

543 Vitaglione P, Mennella I, Ferracane R, Rivellese AA, Giacco R, Ercolini D, Gibbons SM, La

544 Storia A, Gilbert JA, Jonnalagadda S, Thielecke F, Gallo MA, Scalfi L, Fogliano V. 2015.

545 Whole-grain wheat consumption reduces inflammation in a randomized controlled trial on

546 overweight and obese subjects with unhealthy dietary and lifestyle behaviors: role of

547 polyphenolics bounds to cereal dietary fiber. American Journal of Clinical Nutrition 101:251-

548261 DOI 10.3945/ajcn.114.088120.

549 Warnes GR, Bolker B, Bonebakker L, Gentleman R, Wolfgang Huber AL, Lumley Y, Maechler

550 M, Magnusson A, Moeller S, Schwartz M, Venables B. 2015. gplots: Various R Programming 
551 Tools for Plotting Data. 2015, R package version 2.16.0. URL http://CRAN.R-

552 project.org/package $=$ gplots.

553 Walter J, Tannock GW, Tilsala-Timisjarvi A, Rodtong S, Loach DM, Munro K, Alatossava T.

554 2000. Detection and identification of gastrointestinal Lactobacillus species by using denaturing 555 gel electrophoresis and species-specific PCR primers. Applied Environmental Microbiology

556 66:297-303.

557 Wu GD, Lewis JD, Hoffmann C, Chen YY, Knight R, Bittinger K, Hwang J, Chen J, Berkowsky

558 R, Nessel L, Li H, Bushman FD. 2010. Sampling and pyrosequencing methods for characterizing 559 bacterial communities in the human gut using 16S sequence tags. BMC Microbiology 10:206 560 DOI 10.1186/1471-2180-10-206.

561 Zhang H, DiBaise JK, Zuccolo A, Kudrna D, Braidotti M, Yu Y, Parameswaran P, Crowell MD, 562 Wing R, Rittmann BE, Krajmalnik-Brown R. 2009. Human gut microbiota in obesity and after 563 gastric bypass. Proceedings of the National Academy of Sciences of the United States of America 564 106:2365-2370 DOI 10.1073/pnas.0812600106.

Acknowledgements JFGM acknowledges financial support by CONACYT (Mexico) through the National System of Researchers (SNI, for initials in Spanish) program and PRODEP (Mexico). DAM acknowledges the Peter J. Shields Endowed Chair. The authors would like to express our deepest gratitude to the QIIME, Mothur and PICRUSt Developers and Help Forums for the creation of such exceptional computational tools and all the support provided. 
593 TABLES

594 Table 1. Formulation of experimental diets (g/100 g).

\begin{tabular}{lll}
\hline Ingredients & $\begin{array}{l}\text { Lean and } \\
\text { Obese diet }\end{array}$ & $\begin{array}{l}\text { Wheat } \\
\text { diet }\end{array}$ \\
\hline Casein, high nitrogen & 20 & 0.0 \\
L-Cysteine & 0.3 & 0.3 \\
\hline
\end{tabular}


595

\begin{tabular}{lll}
\hline Whole-wheat meal & 0.0 & 87.94 \\
Soybean oil & 7.0 & 7.0 \\
Sucrose & 10 & 0.0 \\
Cornstarch & 39.74 & 0.0 \\
Dyetrose & 13.2 & 0.0 \\
t-Butylhydroquinone & 0.0014 & 0.0014 \\
Cellulose & 5 & 0.0 \\
Mineral mix \#210025 & 3.5 & 3.5 \\
Vitamin mix \#310025 & 1.0 & 1.0 \\
Choline bitartrate & 0.25 & 0.25 \\
Kcal/100g & 376.00 & 387.76 \\
\hline
\end{tabular}

596

597

598

599

600

601

602

603

604

605

606

607

608

609 Table 2. Oligonucleotides used in this study for qPCR analyses.

\begin{tabular}{|c|c|c|c|}
\hline $\begin{array}{l}\text { qPCR } \\
\text { primers }\end{array}$ & Sequence $\left(5^{\prime}-3^{\prime}\right)^{*}$ & Target & Reference \\
\hline HDA1 & ACTCCTACGGGAGGCAGCAGT & $\begin{array}{l}\text { All bacteria (V2-V3 regions, position } \\
339-539 \text { in the } E \text {. coli } 16 \mathrm{~S} \text { gene) }\end{array}$ & Walter et al. 2000 \\
\hline HDA2 & GTATTACCGCGGCTGCTGGCAC & & \\
\hline Bact834F & GGARCATGTGGTTTAATTCGATGAT & Bacteroidetes (Phylum) & Guo et al. 2008 \\
\hline
\end{tabular}




\begin{tabular}{|c|c|c|c|}
\hline Bact1060R & AGCTGACGACAACCATGCAG & & \\
\hline 928F-Firm & TGAAACTYAAAGGAATTGACG & Firmicutes (Phylum) & Bacchetti et al. 2011 \\
\hline 1040firmR & ACCATGCACCACCTGTC & & \\
\hline BifF & GCGTGCTTAACACATGCAAGTC & Bifidobacterium (genus) & Penders et al. 2005 \\
\hline BifR & CACCCGTTTCCAGGAGCTATT & & \\
\hline E. coli $\mathrm{F}$ & CATGCCGCGTGTATGAAGAA & E. coli & Huijsdens et al. 2002 \\
\hline E. coli $\mathrm{R}$ & CGGGTAACGTCAATGAGCAAA & & \\
\hline TuriciF & CAGACGGGGACAACGATTGGA & Turibacter (genus) & Suchodolski et al. 2012 \\
\hline TuriciR & TACGCATCGTCGCCTTGGTA & & \\
\hline RumiF & ACTGAGAGGTTGAACGGCCA & Ruminococcaceae (family) & Garcia-Mazcorro et al. 2012 \\
\hline RumiR & CCTTTACACCCAGTAAWTCCGGA & & \\
\hline FaecaliF & GAAGGCGGCCTACTGGGCAC & Faecalibacterium (genus) & Garcia-Mazcorro et al. 2012 \\
\hline FaecaliR & GTGCAGGCGAGTTGCAGCCT & & \\
\hline Eco1457-F & CATTGACGTTACCCGCAGAAGAAGC & Enterobacteriaceae (family) & Bartosch et al. 2004 \\
\hline Eco1652-R & CTCTACGAGACTCAAGCTTGC & & \\
\hline V1F & CAGCACGTGAAGGTGGGGAC & Akkermansia muciniphila & Collado et al. 2007 \\
\hline V1R & CCTTGCGGTTGGCTTCAGAT & & \\
\hline PrevF & CACCAAGGCGACGATCA & Prevotella (genus) & Larsen et al. 2010 \\
\hline PrevR & GGATAACGCCYGGACCT & & \\
\hline Bfr-F & CTGAACCAGCCAAGTAGCG & Bacteroides fragilis & Liu et al. 2003 \\
\hline Bfr-R & CCGCAAACTTTCACAACTGACTTA & & \\
\hline
\end{tabular}

610

611

612

613

614

615

616

617

618

619

620 Table 3. Metabolic features in Lean $(n=11)$, Obese $(n=9)$ and whole-wheat supplemented $(n=10)$

621 mice that reached statistical significant differences (ANOVA, $p<0.01$ adjusted for False

622 Discovery Rate in STAMP).

Treatment Groups 
KEGG gene categories

\begin{tabular}{|c|c|c|c|c|c|c|}
\hline Level_1 & Level_2 & Level_3 & Mean \pm st. dev. & Mean \pm st. dev. & Mean \pm st. dev. & $\begin{array}{c}p \\
\text { value }\end{array}$ \\
\hline $\begin{array}{l}\text { Cellular } \\
\text { Processes }\end{array}$ & $\begin{array}{l}\text { Transport and } \\
\text { Catabolism }\end{array}$ & Peroxisome & $0.15 \pm 0.03^{\mathrm{a}}$ & $0.18 \pm 0.04^{\mathrm{a}, \mathrm{b}}$ & $0.23 \pm 0.03^{\mathrm{c}}$ & 0.001 \\
\hline \multirow{2}{*}{$\begin{array}{l}\text { Environmental } \\
\text { Information } \\
\text { Processing }\end{array}$} & Signal Transduction & $\begin{array}{l}\text { Phosphatidylinositol } \\
\text { signaling system }\end{array}$ & $0.11 \pm 0.01^{\mathrm{a}}$ & $0.08 \pm 0.01^{b}$ & $0.10 \pm 0.01^{\mathrm{a}, \mathrm{c}}$ & 0.002 \\
\hline & $\begin{array}{l}\text { Signaling Molecules } \\
\text { and Interaction }\end{array}$ & Ion channels & $0.05 \pm 0.01^{\mathrm{a}}$ & $0.02 \pm 0.01^{\mathrm{b}}$ & $0.02 \pm 0.01^{\mathrm{b}, \mathrm{c}}$ & $<0.001$ \\
\hline $\begin{array}{l}\text { Genetic } \\
\text { Information } \\
\text { Processing }\end{array}$ & $\begin{array}{l}\text { Replication and } \\
\text { Repair }\end{array}$ & Base excision repair & $0.50 \pm 0.06^{\mathrm{a}}$ & $0.41 \pm 0.03^{b}$ & $0.41 \pm 0.04^{b, c}$ & 0.001 \\
\hline \multirow{4}{*}{$\begin{array}{l}\text { Human } \\
\text { Diseases }\end{array}$} & Infectious Diseases & Tuberculosis & $0.18 \pm 0.02^{\mathrm{a}}$ & $0.13 \pm 0.01^{b}$ & $0.13 \pm 0.02^{b, c}$ & 0.001 \\
\hline & Cancers & Pathways in cancer & $0.07 \pm 0.01^{\mathrm{a}}$ & $0.04 \pm 0.00^{\mathrm{b}}$ & $0.05 \pm 0.00^{\mathrm{b}, \mathrm{c}}$ & $<0.001$ \\
\hline & $\begin{array}{l}\text { Neurodegenerative } \\
\text { Diseases }\end{array}$ & $\begin{array}{l}\text { Amyotrophic lateral } \\
\text { sclerosis (ALS) }\end{array}$ & $0.02 \pm 0.01^{\mathrm{a}}$ & $0.03 \pm 0.01^{\mathrm{b}}$ & $0.04 \pm 0.01^{\mathrm{b}, \mathrm{c}}$ & $<0.001$ \\
\hline & Cancers & Renal cell carcinoma & $0.03 \pm 0.01^{\mathrm{a}}$ & $0.01 \pm 0.00^{\mathrm{b}}$ & $0.01 \pm 0.01^{\mathrm{b}, \mathrm{c}}$ & $<0.001$ \\
\hline \multirow[t]{12}{*}{ Metabolism } & $\begin{array}{l}\text { Carbohydrate } \\
\text { Metabolism }\end{array}$ & $\begin{array}{l}\text { Fructose and mannose } \\
\text { metabolism }\end{array}$ & $1.16 \pm 0.19^{\mathrm{a}}$ & $0.94 \pm 0.08^{b}$ & $0.86 \pm 0.12^{\mathrm{b}, \mathrm{c}}$ & 0.005 \\
\hline & & $\begin{array}{l}\text { Pentose phosphate } \\
\text { pathway }\end{array}$ & $0.92 \pm 0.05^{\mathrm{a}}$ & $0.86 \pm 0.07^{\mathrm{a}, \mathrm{b}}$ & $0.78 \pm 0.06^{\mathrm{c}}$ & 0.002 \\
\hline & $\begin{array}{l}\text { Metabolism of } \\
\text { Cofactors and } \\
\text { Vitamins }\end{array}$ & $\begin{array}{l}\text { Porphyrin and } \\
\text { chlorophyll metabolism }\end{array}$ & $0.55 \pm 0.15^{\mathrm{a}}$ & $0.85 \pm 0.13^{b}$ & $0.66 \pm 0.14^{\mathrm{a}, \mathrm{c}}$ & 0.009 \\
\hline & & Vitamin B6 metabolism & $0.17 \pm 0.02^{\mathrm{a}}$ & $0.20 \pm 0.02^{b}$ & $0.22 \pm 0.01^{\mathrm{b}, \mathrm{c}}$ & $<0.001$ \\
\hline & $\begin{array}{l}\text { Metabolism of Other } \\
\text { Amino Acids }\end{array}$ & $\begin{array}{l}\text { Selenocompound } \\
\text { metabolism }\end{array}$ & $0.40 \pm 0.02^{\mathrm{a}}$ & $0.37 \pm 0.01^{\mathrm{b}}$ & $0.35 \pm 0.01^{\mathrm{b}, \mathrm{c}}$ & $<0.001$ \\
\hline & & $\begin{array}{l}\text { Cyanoamino acid } \\
\text { metabolism }\end{array}$ & $0.23 \pm 0.04^{\mathrm{a}}$ & $0.33 \pm 0.02^{\mathrm{b}}$ & $0.30 \pm 0.06^{\mathrm{b}, \mathrm{c}}$ & 0.002 \\
\hline & & beta-Alanine metabolism & $0.18 \pm 0.04^{\mathrm{a}}$ & $0.22 \pm 0.04$ & $0.28 \pm 0.06^{\mathrm{b}}$ & 0.005 \\
\hline & $\begin{array}{l}\text { Carbohydrate } \\
\text { Metabolism }\end{array}$ & $\begin{array}{l}\text { C5-Branched dibasic } \\
\text { acid metabolism }\end{array}$ & $0.23 \pm 0.06^{\mathrm{a}}$ & $0.32 \pm 0.02^{\mathrm{b}}$ & $0.31 \pm 0.02^{\mathrm{b}, \mathrm{c}}$ & 0.003 \\
\hline & $\begin{array}{l}\text { Biosynthesis of Other } \\
\text { Secondary } \\
\text { Metabolites }\end{array}$ & $\begin{array}{l}\text { Phenylpropanoid } \\
\text { biosynthesis }\end{array}$ & $0.12 \pm 0.03^{\mathrm{a}}$ & $0.20 \pm 0.02^{\mathrm{b}}$ & $0.17 \pm 0.05$ & 0.003 \\
\hline & $\begin{array}{l}\text { Metabolism of } \\
\text { Terpenoids and } \\
\text { Polyketides }\end{array}$ & $\begin{array}{l}\text { Biosynthesis of } \\
\text { ansamycins }\end{array}$ & $0.14 \pm 0.04^{\mathrm{a}}$ & $0.11 \pm 0.02$ & $0.09 \pm 0.02^{\mathrm{b}}$ & 0.006 \\
\hline & $\begin{array}{l}\text { Biosynthesis of Other } \\
\text { Secondary } \\
\text { Metabolites }\end{array}$ & Flavonoid biosynthesis & $0.02 \pm 0.01^{\mathrm{a}}$ & $0.01 \pm 0.00^{\mathrm{b}}$ & $0.00 \pm 0.00^{\mathrm{b}, \mathrm{c}}$ & $<0.001$ \\
\hline & & $\begin{array}{l}\text { Stilbenoid, } \\
\text { diarylheptanoid and } \\
\text { gingerol biosynthesis }\end{array}$ & $0.01 \pm 0.01^{\mathrm{a}}$ & $0.00 \pm 0.00^{\mathrm{b}}$ & $0.00 \pm 0.00^{\mathrm{b}, \mathrm{c}}$ & 0.007 \\
\hline
\end{tabular}

623

624

625

626 Table 4. Median (minimum-maximum) for all short-chain fatty acids (SCFAs). Results are

627 expressed in $\mathrm{mmol} / \mathrm{mg}$ of caecal contents.

\begin{tabular}{lcccc} 
SCFA & Lean & Obese & Whole-wheat & $p$ value \\
\hline Sodium butyrate & $0.97(0.15-2.65)^{\mathrm{a}}$ & $2.91(1.47-4.35)^{\mathrm{b}}$ & $4.27(3.05-6.26)^{\mathrm{b}, \mathrm{c}}$ & $<0.001$ \\
Acetic acid & $10.2(7.7-26.3)$ & $12.0(8.3-18.7)$ & $15.4(10.1-31.9)$ & 0.208 \\
Oxalic acid & $15.14(6.68-18.91)^{\mathrm{a}}$ & $14.60(8.78-28.01)$ & $9.96(6.76-12.15)^{\mathrm{b}}$ & 0.033
\end{tabular}


$\begin{array}{llllll}\text { Succinic acid } & 39.84(15.29-97.63)^{\mathrm{a}} & 22.97(3.86-71.18)^{\mathrm{a}, \mathrm{b}} & 3.12(0.91-63.36)^{\mathrm{c}} & 0.009\end{array}$

628

629 Different letters denote statistical significance. $p$ values come from the Kruskal-Wallis test and

630 multiple comparisons were performed using the Mann-Whitney test and corrected with the

631 Bonferroni method.

632

633

634

635

636

637

638

639

640

641

642

643

644

645

646

647 Figures and figure legends 

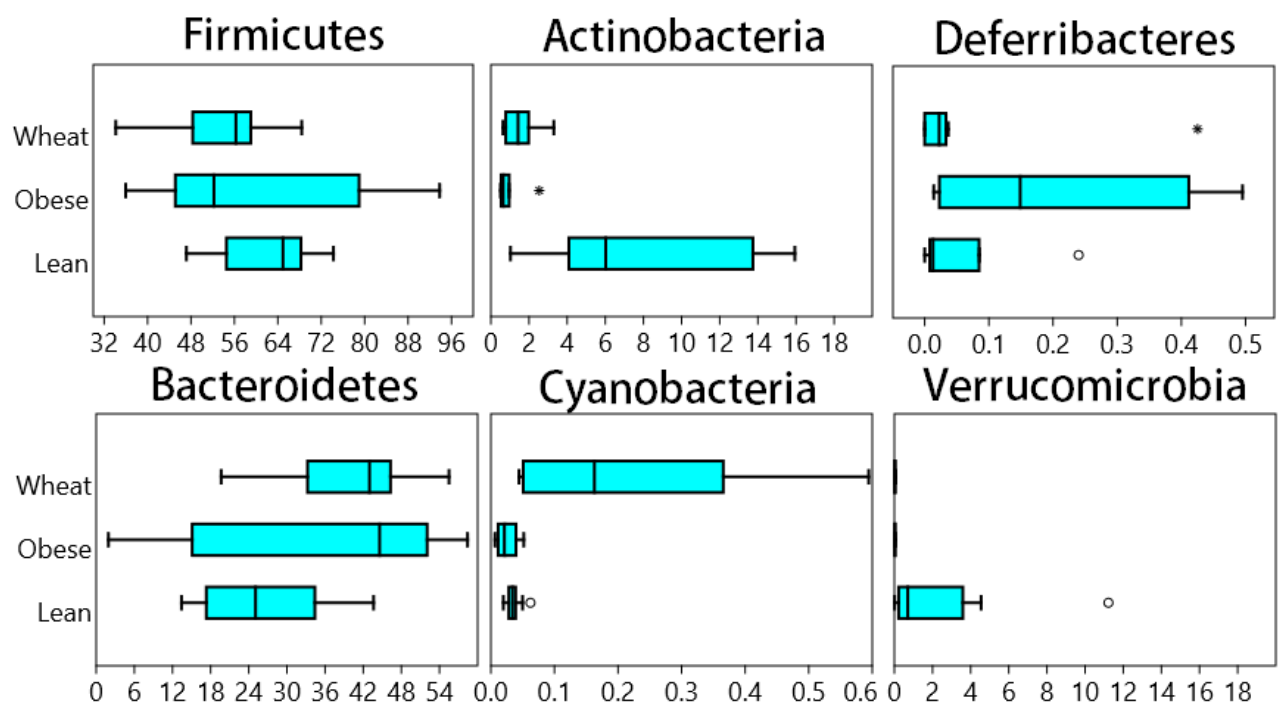

Verrucomicrobia

648
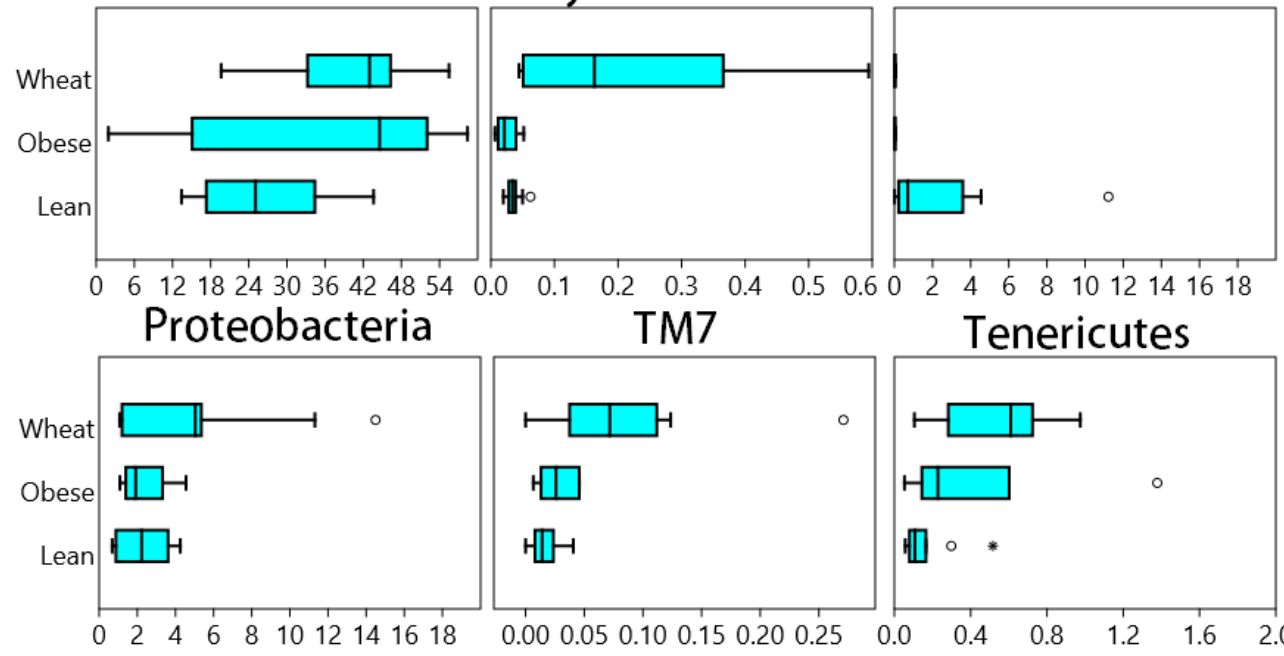

Tenericutes

Figure 1 Box plots. Composition of fecal microbiota at the phylum level in the Lean $(n=11)$, obese control (Obese, $n=9$ ) and whole-wheat (Wheat, $n=10$ ) group. Boxes represent the 25-75 quartiles, the median is shown with a vertical line inside the box. Values outside 1.5 times the box height are shown as circles; values outside 3 times the box height are shown as stars. The differences in relative abundance of Firmicutes, Bacteroidetes and Proteobacteria did not reach statistical significance (see main text for details). 

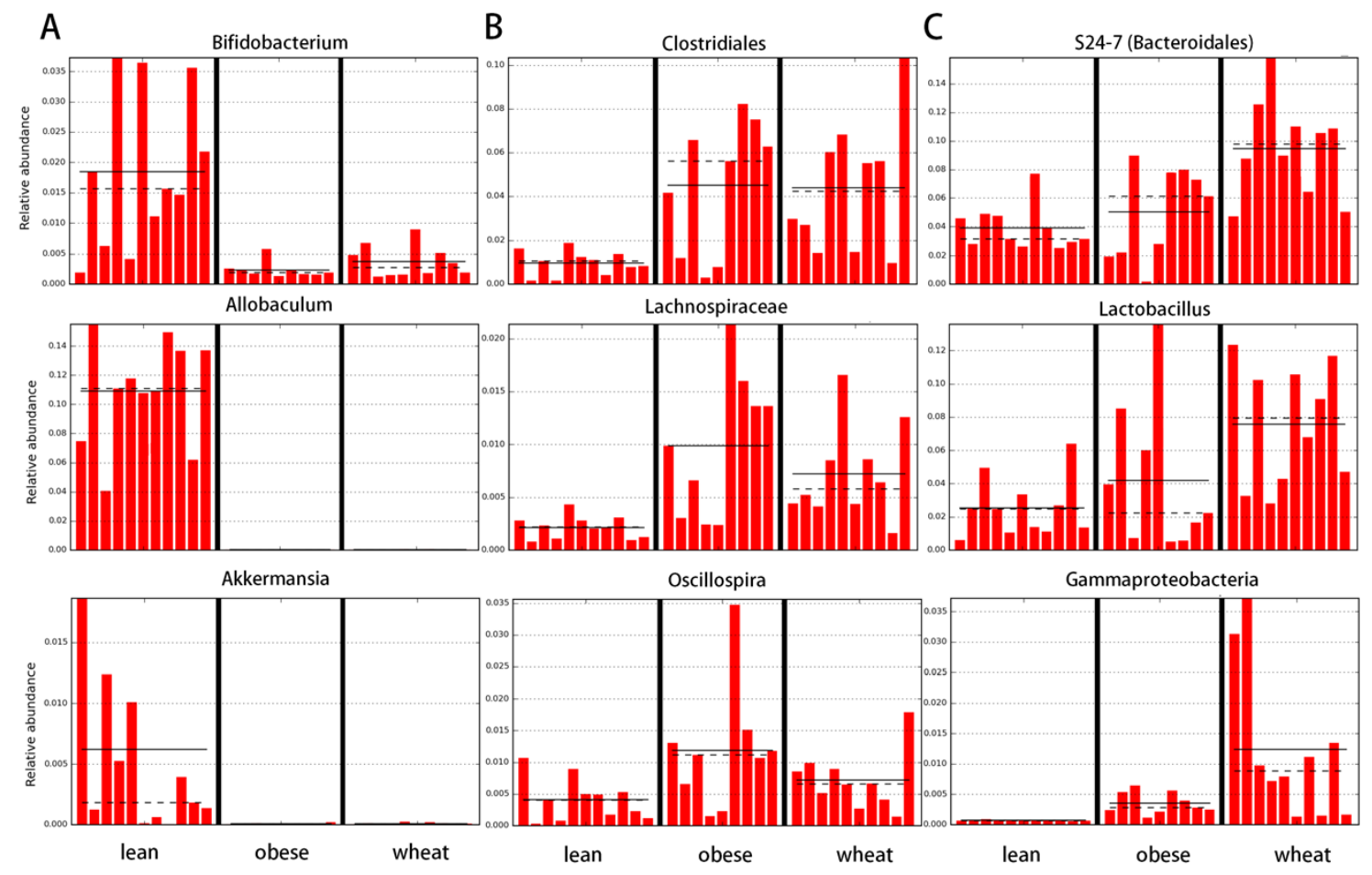

657 Figure 2 Bar charts of most significant results using the LDA effect size method (LEfSe).

658 LefSe identifies those bacterial groups that showed statistical significance effect size and

659 associate them with the class (in this study treatment group) with the highest median. Panel A

660 (left): lean; Panel B (center): obese-control; Panel C (right): WW-supplemented obese mice.

Dotted lines represent medians; straight lines represent averages. 

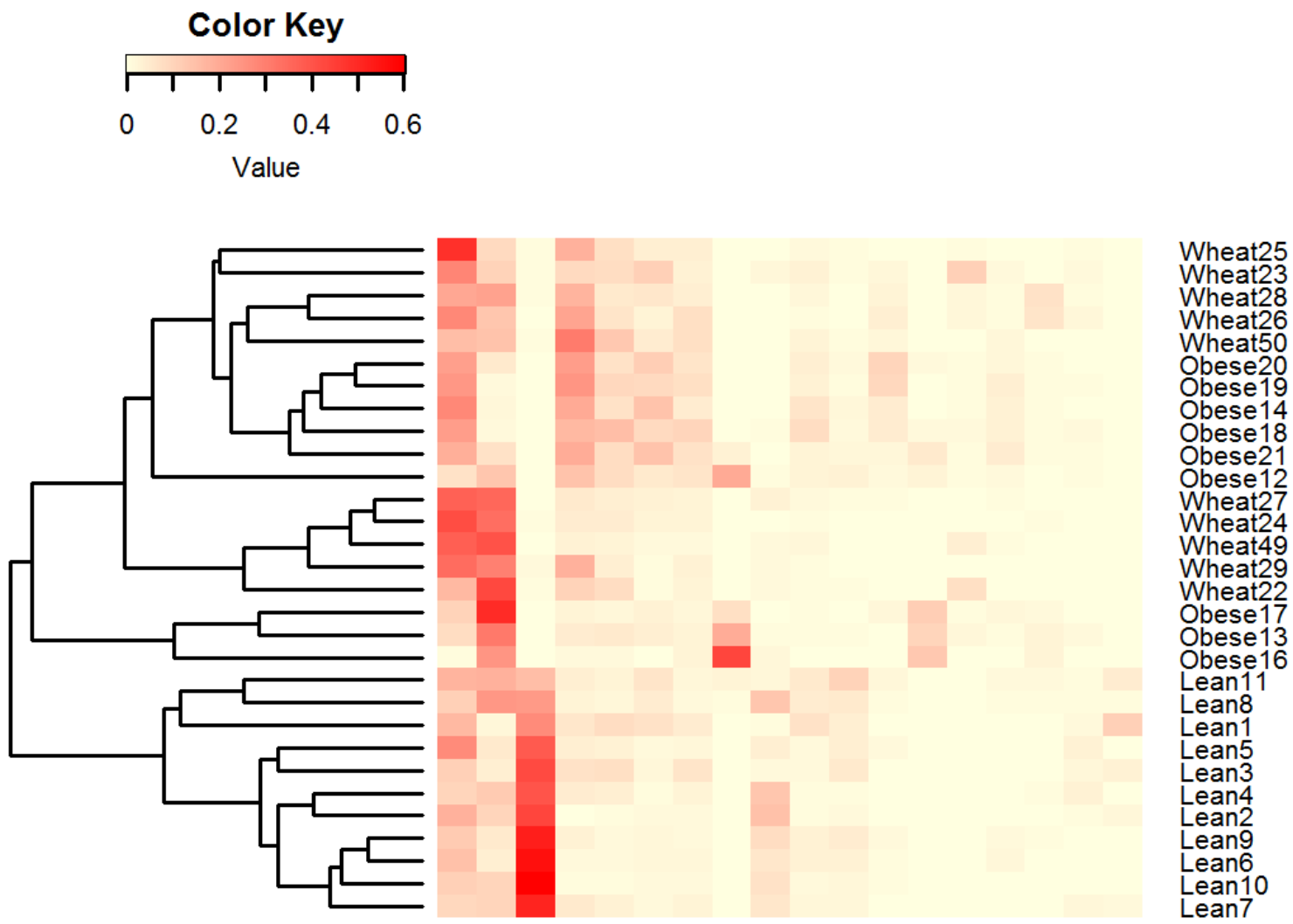

663

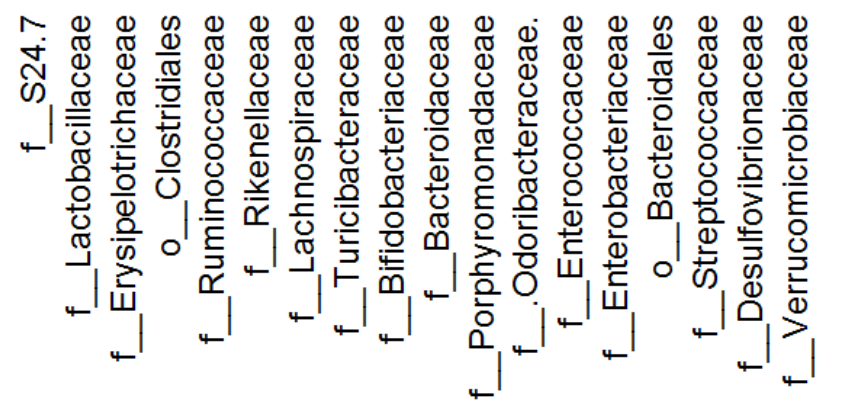

664 Figure 3 Heatmap. Heatmap of relative abundance of the most abundant bacterial taxa at the

665 family level (x axis, ordered by abundance) in Lean $(n=11)$, Obese $(n=9)$ and Wheat $(n=10)$

666 group. This figure shows that lean subjects clustered separately from obese and WW subjects.

667 Clustering was performed using Bray-Curtis distances in R v.3.2.2.

668 


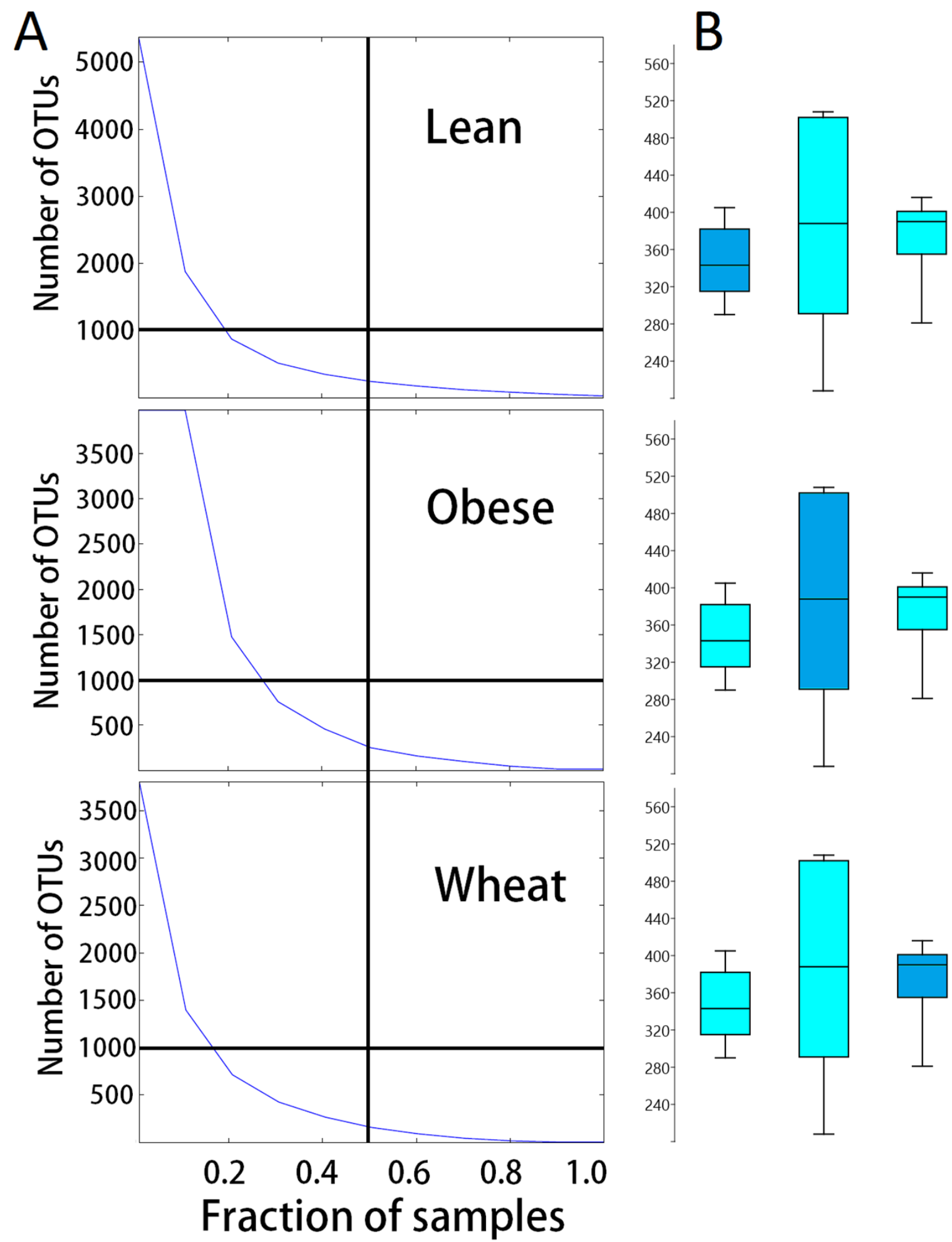

669

670 Figure 4 Dispersion in number of OTUs detected. Panel A (left) shows the relationship

671 between the numbers of OTUs and the proportion of samples containing those OTUs for each 
672 treatment group. These plots show that more obese control samples contained higher numbers of 673 OTUs compared to whole-wheat. Lines were used to illustrate $50 \%$ of the samples (vertical line) 674 and 1000 OTUs (horizontal line). Panel B (right) shows boxplots to illustrate the distributions of 675 the number of OTUs for each treatment group (boxes represent the 25-75 quartiles, the median is 676 shown with a horizontal line inside the box).

677

678

679

680

681

682

683

684

685

686 


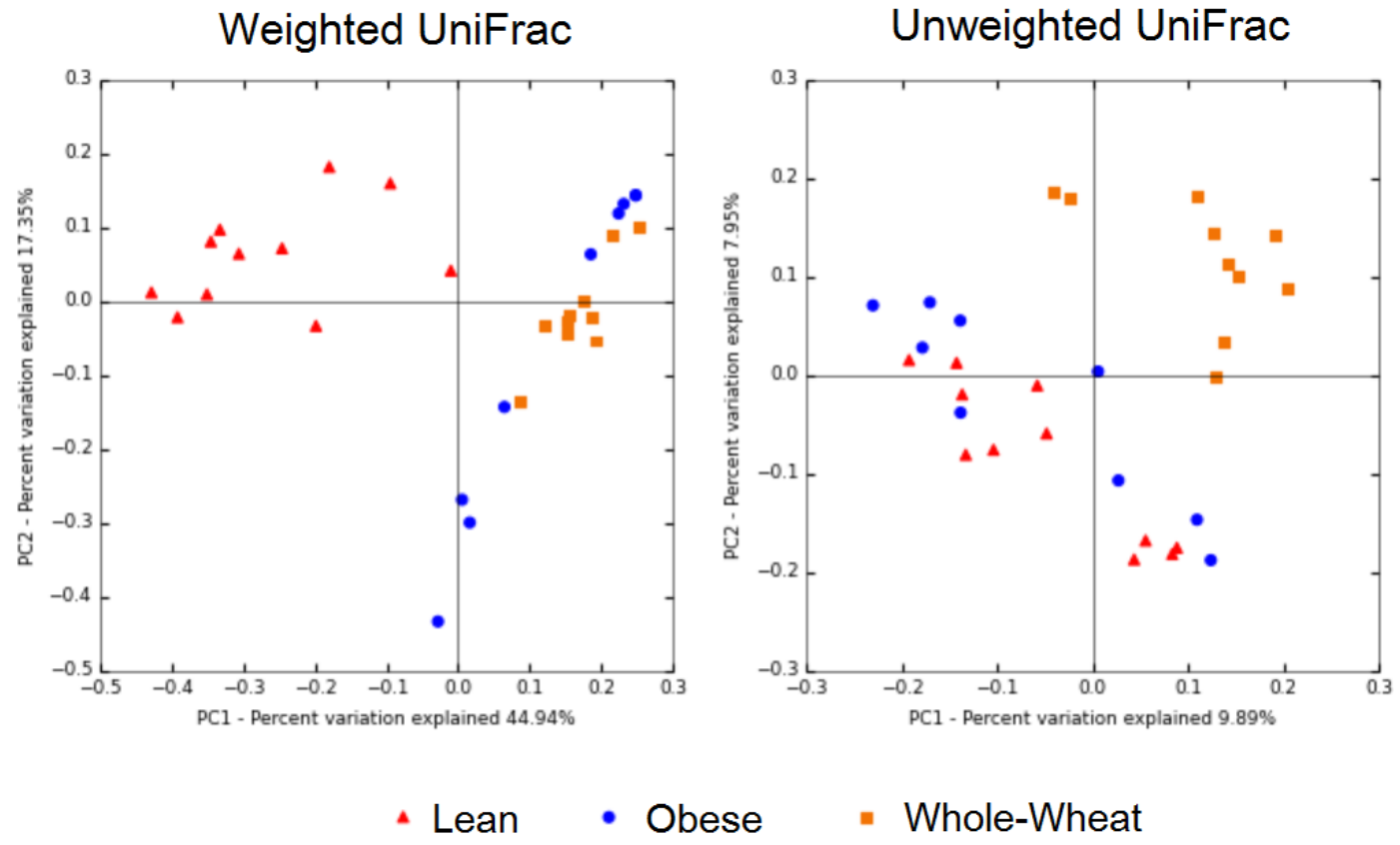

687

688 Figure 5 Principal Coordinates Analysis plots. Principal Coordinates Analysis (PCoA) plots of 689 weighted (left) and unweighted (right) UniFrac distance metrics. Please note that each plot gives 690 contrasting results with regards to the clustering of samples. 


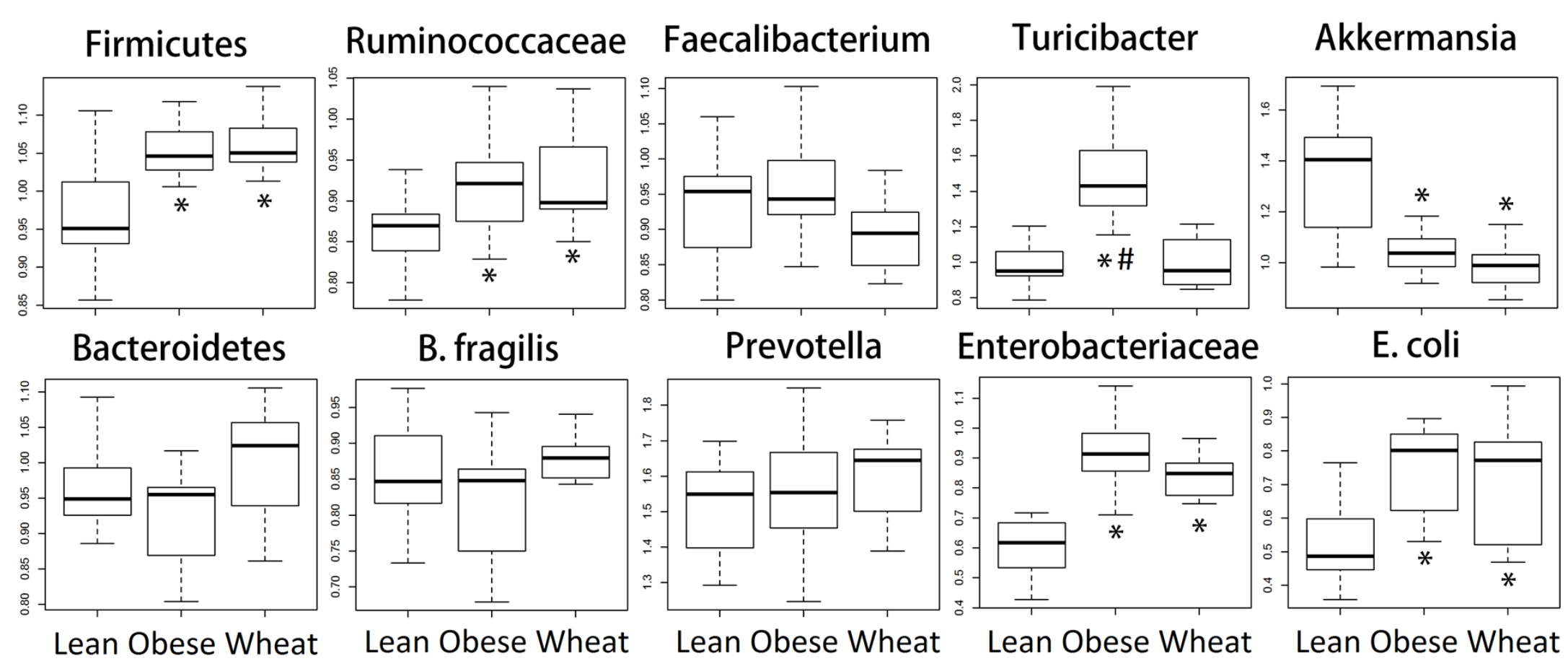

Figure 6 Boxplots. Quantitative real-time PCR (qPCR) results for selected bacterial groups. Results are expressed as relative 